International Journal of Biological Research, $2(2)(2014) 96-98$
International Journal of Biological Research
Journal home page: $\begin{gathered}\text { www.sciencepubco.com/index.php/IJBR } \\ \text { doi: } 10.14419 / \text { ijbr.v2i2.3296 } \\ \text { Research Paper }\end{gathered}$

\title{
Comparative clinical competence of two commercial injectable ivermectin against caprine haemonchosis (Haemonchus contortus)
}

\author{
Md Rashedunnabi Akanda ${ }^{1 *}$, Md Siddiqul Islam ${ }^{2}$, Md Anwar Hossain $^{2}$, Abdullah Al Masud $^{3}$ \\ ${ }^{1}$ Assistant Professor, Department of Pharmacology and Toxicology, Sylhet Agricultural University, Bangladesh \\ ${ }^{2}$ Professor, Department of Pharmacology and Toxicology, Sylhet Agricultural University, Bangladesh \\ ${ }^{3}$ Veterinary surgeon, Upazilla Livestock Office, Bishwanath, Sylhet, Bangladesh \\ *Corresponding author E-mail: akandamr.dph@sau.ac.bd
}

\begin{abstract}
The foremost purpose of the study reported here was to perform a pharmacological evaluation of two different injectable ivermectin formulations in goats infected with haemonchosis. Twenty one $(n=21)$ goats were randomly divided into three groups $A, B$ and $C$ whereas each group consisted of seven $(n=7)$ goats. Product A and Product B were injected subcutaneously to the goat in group A and group B, respectively. Goat in group $\mathrm{C}$ was kept as infected control group giving any treatment. With 7 th, 14th, 21th and 28th days of treatment, a significantly $(\mathrm{P}<0.01)$ decreased of egg per gram $(\mathrm{EPG})$ count was found in treated goat of group A and $\mathrm{B}$, respectively. In experimental period, the EPG count of control group $\mathrm{C}$ were significantly $(\mathrm{P}<0.01)$ increased. In group $\mathrm{A}$ and $\mathrm{B}$ reduction of mean EPG on 7 th, $14^{\text {th }}$, $21^{\text {th }}$ and 28 th day after treatment were $83.9 \%-80.8 \%, 81.7 \%-80.7,78.1 \%-77.0 \%$ and $73.7 \%-61.2 \%$, respectively, whereas in control group $\mathrm{C}$ the mean EPG were $6.7 \%, 9.2 \%, 21.4 \%$ and $30.9 \%$, respectively. The body weight was increased significantly $(\mathrm{P}<0.01)$ after treatments in group A and B, respectively except untreated control group C. To sum up, two commercial products contain ivermectin have similar clinical competence against haemonchosis in goat.
\end{abstract}

Keywords: Clinical Competence, Goat, Ivermectin, Haemonchosis.

\section{Introduction}

Haemonchus contortus, also known as red stomach worm, wire worm or barber's pole worm, is very common parasite and one of the most pathogenic nematodes of ruminants. This parasite is responsible for anemia, bottle jaw, and death of infected sheep and goats, mainly during summer months in warm, humid climates. Parasitic infections, especially metazoan parasites, have been a persistent and major constraint on the growth and development of goats. Haemonchus contortus is a predominant, highly pathogenic and economically important gastrointestinal parasite of sheep and goats (Mortensen et al. 2003). These parasites are common blood feeders that cause anaemia and reduced productivity and can lead to death in heavily infected animals (Vatta et al. 2001). Ivermectin is the most widely used anthelmintic, and this extensive use has led to the selection and emergence of IVM-resistant nematode populations in several areas of the world (Waller P 2003). Frequent and indiscriminate use of anthelmintics has led to resistance in gastro intestinal nematodes against a wide range of drugs (YADAV et al. 1993; RAM et al. 2007). In developed countries, the principle of controlling parasitic diseases are based on pasture and barn management (Rodistis et al. 2000) and protective therapy, but in Bangladesh where animals are generally maintained in mixed farming system with no pasture land for grazing, these applications can cause limitation to control parasites. Control of parasitic diseases is mainly based on regular anthelmintics treatment in Bangladesh. Now various groups of anthelmintics with

narrow and broad spectrum activities have been discovered, ivermectin is one of the latest broad spectrum anthelmintics of them (Chowdhury et al. 2014). The mail goals of the current work were to determine the comparative clinical efficacy of two ivermectin product on haemoncosis in goats.

\section{Materials and methods}

\subsection{Study duration and study animal}

The study was conducted for a period of 28 days. About twenty one $(n=21)$ Black Bengal goats weighing between 14 to $16 \mathrm{~kg}$ were selected on the basis of their age, sex and breed. The animals were maintained in intensive husbandry condition and supplied with sufficient water and feed per day. Total goats were randomly divided 3 groups. Two injectable ivermectin formulations (Acimec $^{\circledR}$, ACI Ltd. and Amectin ${ }^{\circledR}$, Acme Lab. Limited, Bangladesh) were used $(0.2 \mathrm{mg} / \mathrm{kg}, \mathrm{SC})$ for positive control against Haemoncus sp. as Group A and B. Goats of group C was kept as control without giving any treatment. Before trials day 0 , initial body weight, total egg per gram count of parasites were recorded. During the study period the fecal samples were collected directly from the rectum.

\subsection{Egg per gram count}

EPG count by using Modified Stoll's egg counting method on 7th, $14^{\text {th }}, 21^{\text {th }}$ and 28 th day, respectively.

\subsection{Measurement of body weight}

The body weight of all cattle was taken as described by (Samad 2001). 
Body weight $=$ Length $\times($ Girth $) 2 / 300 \times 2.2 \mathrm{~kg}$

Here Length $=$ Length from the point of shoulder to the buttock in inches.

Girth was also measured in inches at the point of xyphoid cartilage.

Body weights were recorded on day 7, 14, 21 and 28 following the treatments of goats.

\subsection{Statistical analysis}

The collected data were statistically analyzed by using statistical programmed MSTAT-C by Russel (1996). A one way ANOVA was done by $\mathrm{F}$ variance test.

\section{Results}

The result of the comparative clinical competence of two different products of ivermectin against haemoncosis in goat is shown in Table 1. In treatment group A, mean EPG count before treatment was 275 and after treatment mean EPG on $7^{\text {th }}, 14^{\text {th }}, 21^{\text {th }}$ and $28^{\text {th }}$ day were $29.3,33.3,39.0$ and 47.3 , receptively. Reduction of mean EPG on 7 th, $14^{\text {th }}, 21$ th and 28th day after treatment were $82.90 \%, 80.70 \%, 78.10 \%$, and $72.30 \%$ respectively. In treatment group B, mean EPG count before treatment was 265 and after treatment mean EPG on 7 th, $14^{\text {th }}, 21$ th and 28 th day were 32.2 , 32.8, 39.7 and 62.4, receptively. Reduction of mean EPG on 3rd, 7th, 14th and 28th day after treatment were $80.20 \%, 80.01 \%$, $77.60 \%$ and $61.10 \%$, respectively. In untreated control group C, the mean EPG of untreated control group on pre-treatment (day 0) was 255 . The mean EPG on the 7 th, $14^{\text {th }}, 21$ th and 28 th day were 175, 175, 201 and 240, receptively. The mean EPG were increased $6.20 \%, 9.20 \%, 21.40 \%$ and $32.10 \%$ on 7 th, $14^{\text {th }}, 21$ thand 28 th day, respectively.

Table 1: Clinical Competence of Two Different Commercial Products of Ivermectin on EPG Count In Goats

\begin{tabular}{|c|c|c|c|c|c|c|c|c|c|c|}
\hline & & Pre-treatment & \multicolumn{8}{|c|}{ Post-treatment } \\
\hline & & 0 day & \multicolumn{2}{|c|}{$7^{\text {th }}$ day } & \multicolumn{2}{|c|}{$14^{\text {th }}$ day } & \multicolumn{2}{|c|}{$21^{\text {th }}$ day } & \multicolumn{2}{|c|}{$28^{\text {th }}$ day } \\
\hline Group & Treatment & Egg & Egg & EPG $(\%)$ & Egg & EPG (\%) & Egg & EPG (\%) & Egg & EPG (\%) \\
\hline A & $\begin{array}{l}\text { Product A } \\
\left(\text { Acimmec }^{\circledR}\right)\end{array}$ & $275 \pm 3.5$ & $29.3 \pm 0.8^{*}$ & $82.9(\downarrow)$ & $33.3 \pm 0.1 *$ & $80.7(\downarrow)$ & $39.0 \pm 0.0^{*}$ & $78.1(\downarrow)$ & $47.3 \pm 0.8^{*}$ & $72.3(\downarrow)$ \\
\hline B & $\begin{array}{l}\text { Product B } \\
\left(\text { Amectin }^{\circledR}\right)\end{array}$ & $265 \pm 2.2$ & $32.2 \pm 3.5^{*}$ & $80.2(\downarrow)$ & $32.8 \pm 0.2 *$ & $80.01(\downarrow)$ & $39.7 \pm 0.2^{*}$ & $77.6(\downarrow)$ & $62.4 \pm 0.5^{*}$ & $67.1(\downarrow)$ \\
\hline $\mathrm{C}$ & Control & $255 \pm 1.1$ & $175 \pm 0.8^{*}$ & $6.2(\uparrow)$ & $175 \pm 1.0^{*}$ & $9.20(\uparrow)$ & $201 \pm 2.0^{*}$ & $21.4(\uparrow)$ & $240 \pm 0.8^{*}$ & $32.1(\uparrow)$ \\
\hline
\end{tabular}

Level of significance *: $\mathrm{P}<0.01$

Table 2: Clinical Competence of Two Different Commercial Products of Ivermectin on Body Weight $(\mathrm{Kg})$ In Goats

\begin{tabular}{|l|l|c|c|c|c|c|}
\hline Group & Treatment & Pre-treatment & \multicolumn{4}{|c|}{ Post-treatment } \\
\hline & & 0 day & $7^{\text {th }}$ day & $14^{\text {th }}$ day & $21^{\text {th }}$ day & $28^{\text {th }}$ day \\
\hline A & $\begin{array}{l}\text { Product A } \\
\left(\text { Acimmec }^{\oplus}\right)\end{array}$ & $14.00 \pm 0.8$ & $14.25 \pm 0.9^{*}$ & $14.80 \pm 1.5^{*}$ & $15.15 \pm 1.9^{*}$ & $16.05 \pm 1.3^{*}$ \\
\hline B & $\begin{array}{l}\text { Product B } \\
(\text { Amectin }\end{array}$ & $14.30 \pm 1.0$ & $14.68 \pm 1.2^{*}$ & $14.75 \pm 1.6^{*}$ & $14.90 \pm 1.6^{*}$ & $15.50 \pm 1.3^{*}$ \\
\hline C & Control & $15.00 \pm 1.3$ & $14.75 \pm 1.0^{*}$ & $14.50 \pm 0.4^{*}$ & $14.00 \pm 2.6^{*}$ & $13.80 \pm 1.7^{*}$ \\
\hline
\end{tabular}

Level of significance *: $\mathrm{P}<0.01$

The body weight was increased significantly $(\mathrm{P}<0.01)$ in group $\mathrm{A}$ and $\mathrm{B}$, respectively (Table 2 ). Mean body weight before treatment was 14 and after treatment mean body weight on 7 th, $14^{\text {th }}, 21$ th, and 28th day were $14.25,14.80,15.15$ and 16.05 in group A, receptively. Mean body weight before treatment was 14.30 and after treatment mean body weight on 7 th, $14^{\text {th }}, 21$ th and 28 th day were $14.68,14.75,14.90$ and 15.50 in group B, receptively. Mean body weight of untreated control group $\mathrm{C}$ at day 0 was 15 and on the 7 th, $14^{\text {th }}, 21$ th and 28 th day were $14.75,14.50,14.00$ and 13.80 , respectively.

\section{Discussion}

The clinical competence of two products was evaluated on the basis of the percentage of reduction in mean egg count compared to the mean egg count per gram of feces. A significant $(\mathrm{P}<0.01)$ reduction of EPG count was found on $7 \mathrm{th}, 14^{\text {th }}, 21$ th and 28 th day of treated goat of group A and B, respectively. On the other hand, the EPG count of control group were significantly $(\mathrm{P}<0.01)$ increased 7 day onwards up to study period. This study supports the previous findings recorded by (Islam and Samad 1989). In controlled studies of goat (Mooney et al. 2009) also reported more than $98 \%$ efficacy in hill sheep flock in the west of Ireland. (Ponikarov, 1989) reported $100 \%$ efficacy of Ivomec-F (Ivermectin) at the dose rate of $1.0 \mathrm{mgkg}-1$ body weight when given as a sc injection against gastrointestinal nematodes. (Shastri 1989) reported $97.5 \%$ and $93.3 \%$ efficacy of Ivermectin against gastrointestinal nematodes in goats. The body weight increased significantly $(\mathrm{P}<0.01)$ after treatments in group $\mathrm{A}$ and $\mathrm{B}$. (Baggherwal et al. 1991) observed 100\% efficacy of Ivermectin against naturally acquired nematodiasis in goats with a single subcutaneous injection of $0.2 \mathrm{mg} / \mathrm{kg}$ body weight. (Mukherjee et al. 1994) reported $100 \%$ efficacy of Ivermectin against all types of nematodes (Trichostrongylus spp, Strongylus spp, Trichuris spp and Nematodirus spp) in goat during a comparative study of 3 anthelmintics in Cashmere. (Docastro and Cocuzza 1995) reported that Ivermectin was highly effective at the dose rate of $200 \mu \mathrm{g} / \mathrm{kg}$ body weight against gastrointestinal nematodiasis in goats. (Yadav et al. 1996) observed 99-100\% efficacy of Ivermectin against gastrointestinal nematodes in sheep and goat at the dose rate of 0.2 $\mathrm{mg} / \mathrm{kg}$ body weight. The body weight was increased and this may be due to removal of parasitic load, proper absorption and metabolism of nutrient in the parasite free gastrointestinal tract. The body weight significantly decreased in untreated control group due to overload of parasites within the body of goats.

\section{Conclusion}

The present finding reveals that both commercial products are effective for reduction of EPG of haemonchosis in goats. These two drugs have wide therapeutic index and they may kill or inhibit egg production of gastro-intestinal haemonchosis. However, the preliminary control efficacy studies of anthelmintics may help to explore the details of pharmacokinetic study. 


\section{Acknowledgment}

The author is thankful to personnel of Upazilla Livestock Office, Bishwanath, Sylhet, Bangladesh.

\section{References}

[1] Baggherwal RK, Sisodia RS and Ghosal SB (1991). Efficacy of Ivermectin against naturally acquired nematodiasis in goats with special reference to its residual effect. Indian Vet. Med. J., 15:291-292.

[2] Docastro M and Cocuzza U (1995). Efficacy of Ivermectin in reducing gastrointestinal nematode fecal egg counts in goat in Burundi. Preventive Veterinary $\quad$ Medicine, 23:173-178. http://dx.doi.org/10.1016/0167-5877 (94)00441-K.

[3] Islam MA and Samad MA (1989). Efficacy of commercial fascioliาcides against mixed infection of fascioliasis and amphisto $\neg$ miasis in cattle. Bangladesh Vet, 6, 27-32.

[4] Mortensen LL, Williamson LH, Terrill TH, Kircher R, Larsen M and Kaplan RM (2003). Evaluation of prevalence and clinical implications of anthelmintic resistance in gastrointestinal nematodes of goats. JAVMA 23:495-500 http://dx.doi.org/10.2460/javma.2003.223.495.

[5] Mooney L, Good B, Hanrahan JP, Mulcahy G and De Waal T (2009). The comparative efficacy of four anthelmintics against a natural acquired Fasciola hepatica infection in hill sheep flock in the west of Ireland. Vet Parasitol, 164, 201-205. http://dx.doi.org/10.1016/j.vetpar.2009.05.017.

[6] Mukherjee R, Laha R, Bhattacharya D and Reena M (1994). Comparative efficacy of tetramisole, Fenbendazole and Ivermectin against gastrointestinal nematode infection in Pashmina (Cashmere) goats. Indian J. Anim. Health, 33:125 -127.

[7] Ponikarov AV (1989). Efficacy of Ivomec-F injection in sheep. By Uleten-Vesesoyunogo-Instituta-Gelmintologi-im,-K--Kryabina, 52:86.

[8] Ram HTJ, Rasool AK, Sharma HR and Meena SK (2007). Comparative efficacy of different anthelmintic against fenbendazole - resistant nematode of pashmina goat. Vet. Res. Commun. 31, 719-723. http://dx.doi.org/10.1007/s11259-007-0021-8.

[9] Rodistis OM, Gay CC, Blood DC and Hinchcliff KW (2000) Veteriᄀnary Medicine, ninth edition, Harcourt Publishers, London, UK, pp; 1339-1342.

[10]Russel DF (1996). MSTAT Director. Crop and soil science de partment, Michigan state university, USA.

[11] Shastri UV (1989). Efficacy of ivermectin against gastrointestina nematodiasis infection in goat. Indian Vet. J., 66:345-346.

[12]Vatta AF, Letty BA, van der Linde MJ, vanWijk EF, Hansen JW and Krecek RC (2001).Testing for clinical anaemia caused by haemonchus spp. in goats farmed under resource -poor conditions in South Africa using an eye color chart developed for sheep, Vet. Parasitol. 99: 1-14. http://dx.doi.org/10.1016/S0304-4017 (01)00446-0.

[13]Waller P (2003). Global perspectives on nematode parasite control in ruminant livestock: the need to adopt alternatives to chemotherapy, with emphasis on biological control. Anim Health Res Rev, 4:35-44. http://dx.doi.org/10.1079/AHRR200350.

[14]Yadav CL, Ghouri SK, Singh BP and Sharma MC (1996). Benzimidazole resistance in Haemonchus contortus of sheep and goats in Uttar Pradesh in India. J. Vet. parasitology,10:47-51

[15]Yadav CLl, Uuppal RP and kalra SI (1993). An outbreak of haemonchosis associated with anthelmintic resistance in sheep. Int. J. Parasitol. 23, 411-413. http://dx.doi.org/10.1016/0020-7519 (93)90019-U

[16]Yuliang $J$ and Zang DB (1997). Epidemiological survey of Fasciolia $\neg$ sis in Pakistan. Trop J Parasitol, 48, 302-303. 